were demonstrated in normal subjects. ${ }^{1}$ Sir Thomas Lewis showed in $1927^{2}$ that intracutaneous morphine elicited a triple response similar to that induced by histamine. Histamine release by opium alkaloids has been demonstrated in isolated cat skin and muscle preparations. ${ }^{3}$ Elevated plasma levels of histamine have been measured in intact dogs following the administration of morphine and pethidine. ${ }^{4} \mathrm{~A}$ significant decrease in the lung capacity of intact dogs has been observed following the administration of morphine and pethidine-an effect most likely to be due to bronchoconstriction. ${ }^{5}$ The mechanism of opiate-induced bronchoconstriction may include central vagal stimulation, histamine release leading to enhanced bronchomotor tone and pulmonary vascular congestion, and histamineinduced reflex enhancement of vagal tone. ${ }^{5}$

In view of this evidence and the availability of alternative sedatives, we feel that the use of opium alkaloids in asthma is unjustified and should be avoided.-We are, etc.,

\section{S. LAKSHMINARAYAN}

S. A. SAHN L. D. HudsoN

Division of Pulmonary Diseases,
University of Colorado Medical Center,

Denver, Colorado 1 Higgins, H. L., and Means, J. H., Fournal of

2 Lewis, T, T., The Blood Vessels of the Human Skin and Their Responses. London, Shaw and Sons,

3 Feldberg, W., and Paton, W. D. M., Fournal of Physiology, 1951, 114, 490.

Thompson, W. L., and Walton, R. P.. Fournal of 1964, 143, 131. and Experimental Therapeutics, 5 Shemano, I., and Wendel, H. J., Fournal of Pharmacology

\section{Treatment of Typhoid}

SIR,-We read with interest the article on chloramphenicol combined with ampicillin in the treatment of typhoid by Professor F. De Ritis and others (7 October, p. 17). We conducted a similar trial in Madras. ${ }^{1}$ The patients were studied in three treatment groups: group 1 was given chloramphenicol alone $(30 \mathrm{mg} / \mathrm{kg} /$ day); group 2 ampicillin alone $(125 \mathrm{mg} / \mathrm{kg} /$ day); and group 3 a combination of chloramphenicol $(20 \mathrm{mg} / \mathrm{kg} /$ day $)$ and ampicillin $(80 \mathrm{mg} / \mathrm{kg} /$ day $)$. The mean duration of pyrexia after starting the treatment in the three groups was $5 \cdot 6,4 \cdot 8$, and 5.4 days respectively. Though the difference between the treatment groups was not significant the average dose of chloramphenicol and ampicillin was smaller in group 3. If the patients had been given full doses of chloramphenicol and ampicillin, as in the study of Professor De Ritis and his colleagues, the pyrexial period might have been shortened significantly. Furthermore, the need for steroid supplementation to control toxaemia after antibacterial treatment only for the first 72 hours was less in those on combined therapy than in those on chloramphenicol alone or ampicillin alone. One patient in each of the first two groups relapsed and none in the third group.

We also studied the use of furazolidone in enteric fever in a similar wav. ${ }^{2}$ Patients in group 2 were given chloramphenicol $(43.5 \mathrm{mg} / \mathrm{kg} /$ day); those in group 2 were given furazolidone alone $(17 \mathrm{mg} / \mathrm{kg} / \mathrm{dav})$; and those in group 3 chloramphenicol (39 $\mathrm{mg} / \mathrm{kg} /$ day $)$ and furazolidone $(12.5 \mathrm{mg} / \mathrm{kg} /$ day). The mean duration of pyrexia after starting treatment was $4.6,5.9$, and 3.5 days respectively, the difference being statistically significant in favour of the combined therapy. No patients in group 3 relapsed, but one did so in each of the other groups.

Combined therapy seems therefore to be superior to single drug therapy. The possible advantage of a reduced dosage of the individual drugs in the combination, especially of chloramphenicol, is also to be considered. With an increasing number of reports of resistance of Salmonella typhi to chloramphenicol it will probably be wiser to start patients, at least those who are very ill, on all three drugs, as it is done in some other infections. When economy is also a consideration chloramphenicol and furazolidone, being cheaper, can be given in preference to the combination containing ampicillin.-We are, etc.,

\section{K. V. THIRUVENGADAM N. SUbramanian A. V. S. SHARMA Sharmila KRISHNASWAMY} S. NALINI

Stanley Medical College,

Madras, India

1 Thiruvengadam, K. V., Subramaniam, S., Krishnaswamy, S., Subramanian, N., and Sarma, A. V. S., Fournal of the Asso

Thiruvengadam, K. 'V., Subramanian, N., and Sarma, A. v. S., fournal of the Association of Physicians of India, 1971, 19, 855 .

\section{Constraints on Consultants}

SIR,-I disagree with the first sentence of your leading article ( 3 March, p. 501), in which you say that the consultant alone has the right to decide on the line of treatment for his patients.

In my opinion the patient has the right to accept or reject a particular line of treatment even when it has been explained to and understood by him. If he is not capable of accepting or rejecting treatment by virtue of his understanding or disposition such decision should be made by his next of kin. This is the procedure adopted in surgical and in medical wards but does not dispose entirely of the ethical and legal hazards.

The only exceptions to such procedure are urgent necessity of saving life or mitigation of disruptive social behaviour.-I am, etc.,

Harpenden, Herts

Harold Palmer

SIR,-If the concept that schizophrenia is caused by the family environment is indeed correct, then surely the appropriate solution should be group family therapy. It is therefore astonishing that you should be able in your criticism (3 March, p. 501) of the Napsbury experiment to state that the purpose of treatment was not even adequately explained to patients' relatives. There seems to have been a clear disparity between theory and practice.-I am, etc.,

Weybridge, Surrey

I. ATKIN

\section{Graphic Records in Labour}

SIR,-I welcome your publication of the Addington Labour Observation Chart and would like to present another example (see fig.). This chart has been successfully used at Charing Cross Hospital for the past four years in Professor N. F. Morris's unit. It is part of the notes, which are in book form, and can be extended indefinitely with identical adhesive sheets (The gum is behind the right hand edge.)

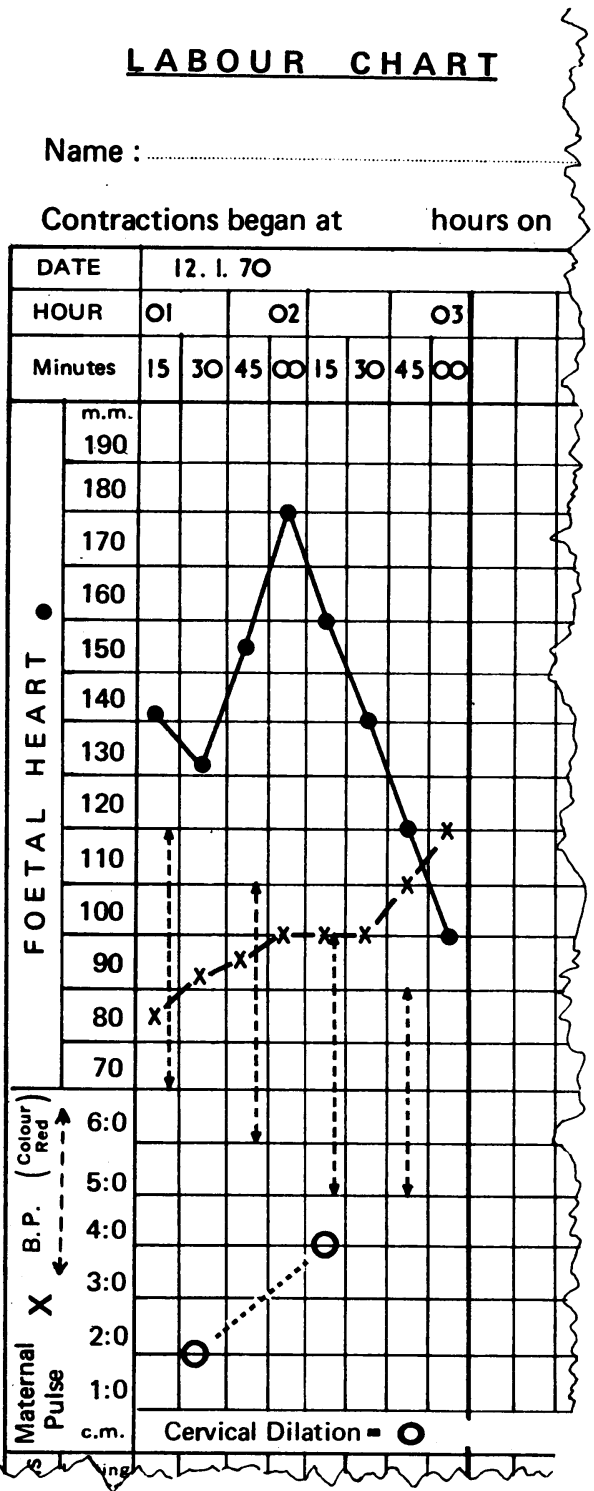

The main advantage is compactness, which has been achieved by including fetal heart, maternal pulse and blood pressure, and cervical dilation on the same graph. Clarity is retained by using red or black symbols and, rather surprisingly, the graphs do not often conflict. The time scale at the top is infinitely variable, permitting flexible spacing of observations, which is particularly useful during crises.

Considerations of space preclude the reproduction of the whole chart here, though I would be pleased to supply copies of this. The lower half includes space for recording the following: contractions (duration, interval, and strength); oxytocin (concentration and rate); drugs given (dosage); fluid intake (oral and intravenous); urine output (volume and abnormalities); and station of fetal head. The chart was designed to measure $8 \frac{1}{2}$ in $\times 11$ in $(21.6 \mathrm{~cm} \mathrm{x} 28 \mathrm{~cm})$ but, if applied to the new standard A4 paper, an extra $\frac{3}{4}$ in $(1.9 \mathrm{~cm})$ becomes available. 